\title{
Muscle and Brown Adipose Tissue Fatty Acid Profiles in Cold-Exposed Rats
}

\author{
Koji Ogawa, Tomie Ohno, ${ }^{*}$ and Akihiro Kuroshima** \\ Laboratory of Physical Education, Hokkaido Tokai University, \\ Asahikawa, 070 Japan \\ * Laboratory of Nutrition Physiology, Hokkaido University \\ of Education, Asahikawa, 070 Japan \\ ** Department of Physiology, Asahikawa Medical College, \\ Asahikawa, 078 Japan
}

\begin{abstract}
Effects of cold acclimation and cold exposure for 25 generations on triglyceride (TG)-, total phospholipid (PL)-, and cardiolipin (CL)-fatty acid (FA) compositions were studied in the different types of skeletal muscles (red and white muscles from quadriceps, and soleus) as well as brown adipose tissue (BAT) in rats. TG: in cold-acclimated rats (CA) and rats reared in cold for 25 generations $(25 \mathrm{G})$ white muscle showed the decreased saturated FA (SA) and increased polyunsaturated FA (PU). In soleus of 25G, monounsaturated FA (MU) and PU increased, and SA decreased. In BAT, SA increased and MU decreased in $\mathrm{CA}$, and SA and PU decreased, and MU increased in 25G. PL: in red muscle of CA, SA increased and PU decreased. In red muscle of $25 \mathrm{G}$ the similar but more marked changes were found accompanied by lowered arachidonic acid and unsaturation index (UI). In BAT, SA, PU, arachidonic acid, and UI increased in CA, and arachidonic acid increased in 25G. CL: in red and white muscles of $25 \mathrm{G}$, oleic acid and $\mathrm{MU}$ increased. In BAT, arachidonic acid increased in CA and $25 \mathrm{G}$, and UI increased in $25 \mathrm{G}$. These results suggest that FA unsaturation of $\mathrm{CL}$ in the muscles as well as BAT is involved in an enhanced thermogenesis in cold-exposed rats.
\end{abstract}

Key words: cold, muscle, brown adipose tissue, fatty acid composition, cardiolipin.

Nonshivering thermogenesis (NST) is a well-documented phenomenon in cold acclimation and its main site of occurrence is evidenced to be brown adipose tissue (BAT) (Foster and Frydman, 1979). Shivering thermogenesis is replaced by

Received for publication August 20, 1987

** To whom correspondence and reprint requests should be addressed. 
nonshivering thermogenesis in the cold-acclimated rats. However, cold acclimation in small mammals such as rats and guinea pigs has been shown to cause certain changes suggesting an enhanced thermogenesis in skeletal muscles. Skeletal muscles manifest increased cytochrome level, cytochrome oxidase, and succinate dehydrogenase activities in the cold-acclimated guinea pigs (KInNula et al., 1983). Total volume and number of mitochondria are found to increase in the skeletal muscle of cold-acclimated rats (BEHRENS and Himms-HaGeN, 1977; YaHATA and KuROSHIMA, 1977). Skeletal muscles from cold-acclimated rats also exhibited increased oxidative enzyme (succinate dehydrogenase), lipid metabolic enzyme ( $\beta$-hydroxybutyrate dehydrogenase) (Pollock et al., 1973), Na, K-ATPase (Guernsey and Stevens, 1977), lipoprotein lipase (BEGIN-HEICK and HEICK, 1977) activities and myoglobin concentration (OHNO and Kuroshima, 1986). Cold exposure (JANSKÝ and HART, 1963) and infusion of noradrenaline, a main regulating factor of nonshivering thermogenesis (JANSKÝ and HART, 1963; GRUBB and FOLK, 1976), were reported to stimulate oxygen consumption of the perfursed skeletal muscle of cold-acclimated rats. From these findings, therefore, it is surmised that skeletal muscles also, at least in part, contribute to an enhanced NST due to cold acclimation, although the direct evidence of skeletal muscle involvement is not yet available. Major energetic substrate for NST has been shown to be fatty acids (LAFRANCE et al., 1980). Intramuscular triglyceride (TG) has been also shown to be an important energy source during prolonged exercise of moderate intensity (SPRIET et al., 1985). It has been postulated that there may be preferential mobilization as well as utilization of fatty acids from the depot TG of adipose tissues (HOLLENBERG and Douglas, 1962; PAUlSRUd and Dryer, 1968; HunTER et al., 1970). On the other hand, fatty acids in phospholipids (PL) are well known to serve as important membrane elements of cell, influencing cellular function with their changes in profile (THOMAs et al., 1977; SPECTOR and YoReK, 1985). Therefore, it may be expected that certain changes in tissue fatty acid compositions would ensue in cold acclimation to meet an increased heat production. Several reports described significant changes in triglyceride fatty acid (Moriya and ItOH, 1969; Williams and Platner, 1967) and phospholipid fatty acid (RIQUiER et al., 1976) profiles in BAT of cold-acclimated animals. However, so far as we know, no work has investigated the changes in fatty acid composition in skeletal muscles. The present study was undertaken to examine the effect of cold acclimation on fatty acid profile in TG, PL, and cardiolipin, which is a specific component of mitochondrial inner membrane, of the skeletal muscles as well as BAT. Special attention was given to the changes in the different types of muscles, because it has been shown that different types of skeletal muscle do not always respond equally to the same physiological stimuli such as exercise (HARMS and Hickson, 1983), thyroid hormone (WINDER and Holloszy, 1977), and cold (Debris and Filipchenko, 1975; Begin-Heick and Heick, 1977; Kurahashi and Kuroshima, 1978). 


\section{MATERIALS AND METHODS}

Animals. Male Wistar rats (Shizuoka Laboratory Animal Center, Hamamatsu) were used in the study. The animals were 7 weeks old, weighing about $180-190 \mathrm{~g}$, at the start of the experiment. The rats were housed at $25 \pm 1{ }^{\circ} \mathrm{C}$ (warm controls, WC) or $5 \pm 1^{\circ} \mathrm{C}$ (cold-acclimated rats, CA) for 4 weeks under the artificial lighting from 7:00-19:00 and provided ad libitum with laboratory rat chow (Oriental MF, Oriental Yeast Co., Ltd., Tokyo) and tap water. Rats reared in cold for 25 generations were also prepared as described elsewhere (MORIYA et al., 1985). These animals were matched for age of other groups at the time of sacrifice. These animals had been shown to exhibit greater NST than the usual coldacclimated rats exposed to cold for 1 generation.

Sampling of tissues. The animals were killed by decapitation. Samples of the superficial white quadriceps, the deep red quadriceps, the soleus, and the interscapular BAT were removed and 100 to $200 \mathrm{mg}$ of the tissue was placed in a glass tube containing 5 to $7 \mathrm{ml}$ of chloroform-methanol $(\mathrm{v} / \mathrm{v}=2: 1)$ lipid extraction solution. The tube was gassed with $\mathrm{N}_{2}$, sealed and kept at $-70^{\circ} \mathrm{C}$ until analyzed.

Analytical methods. Tissue lipids were extracted essentially by the procedure of FolCH et al. (1957). The tissue was homogenized with glass homogenizer in the ice-cold lipid extract solution (ca. 50 volumes). The homogenate was filtered through a fat-free filter paper. The residue was again extracted with ca. 20 volumes of extract solution. The combined extract was washed by mixing with 0.2 its volume of water and allowed to separate into two phases by standing under $\mathrm{N}_{2}$ at $-30^{\circ} \mathrm{C}$ for one night. The lower chloroform phase was evaporated to dryness under $\mathrm{N}_{2}$ in the water bath at room temperature, then taken up in an appropriate volume of extract solution. The separation of the lipid classes was performed by thin-layer chromatography by the method of SKIPSKI and BARCLAY (1969) for TG and PL, and by the method of SimON and Rouser (1967) for CL.

Fatty acids in triglyceride and phospholipid were transesterified by the method of Morrison and SMITH (1964).

The fatty acid methyl esters were analyzed by using Hitachi Model 663-30 gas chromatograph equipped with Hitachi Model 883A data processor with a 2-m glass column containing chromosorb W-AW-DMCS-FFAP (Gaskuro Kogyo Inc., Tokyo). The column was operated at $220^{\circ} \mathrm{C}$. Quantitative standardization of the chromatograph was based on analysis of fatty acid standard methyl ester mixures from $\mathrm{Nu}$-Chek-Prep, Inc.

Calculations. Fatty acid composition was expressed by mol\%. Unsaturation index (UI): the average number of double bonds per fatty acid molecule as indicated by $\Sigma M_{\mathrm{i}} N_{\mathrm{i}} / 100\left(M_{\mathrm{i}}, \mathrm{mol}_{\%} \%\right.$ of each fatty acid; $N_{\mathrm{i}}$, number of double bond of each fatty acid). Arachidonate index (AI): arachidonate $\mathrm{mol} \% /$ linoleate $\mathrm{mol} \%$; AI has been equated with an effect on the elongation-desaturation pathway (MAK et al., 1983).

Statistics. Statistical significance was determined by Student's $t$-test, and the 
difference assumed to be significant at $p<0.05$ where not indicated.

Abbreviations. C14, myristate; C16, palmitate; C16:1, palmitoleate; C18, stearate; $\mathrm{C} 18: 1$, oleate; $\mathrm{C} 18: 2$, linoleate; $\mathrm{C} 18: 3$, linolenate; $\mathrm{C} 20: 4$, arachidonate.

\section{RESULTS}

Fatty acid composition of rat chow

Table 1 shows fatty acid (FA) composition of rat food. No arachidonate was found in both TG and PL fractions.

Fatty acid compositions in the skeletal muscles of warm controls (Figs. 1,2)

In TG-FA the similar proportions of saturated FA (SA), monounsaturated FA (MU), and polyunsaturated FA (PU) were observed in white and red quadriceps. Soleus exhibited higher PU and UI than those of white $(p<0.01)$ and red $(p<0.02)$ quadriceps. No significant differences in MU were found between the muscles. In PL-FA red quadriceps showed higher PU $(p<0.001)$ than white quadriceps. PU of soleus had the intermediate values of white and red quadriceps. MU was similar among the muscles. UI of PL was significantly greater $(p<0.01)$ in red quadriceps than in white quadriceps, but not soleus.

In all skeletal muscles examined, SA and PU were higher $(p<0.001)$ in PL fraction and $\mathrm{MU}$ was lower $(p<0.001)$ than in TG fraction. UI and $\mathrm{AI}$ $(p<0.01-0.001)$ were also higher in the former.

$C L$ (Table 2). PU and UI in CL were markedly higher $(p<0.001)$ in all muscles examined than those in PL (Fig. 2). This resulted from higher C18:2 $(p<0.001)$ in $\mathrm{CL}$, and $\mathrm{C} 20: 4$ was rather lower $(p<0.001)$ in $\mathrm{CL}$ as compared with that in PL. SA and AI in CL $(p<0.001)$ were significantly lower than those in PL. The extent of unsaturation as assessed by $\mathrm{C} 18: 2$, UI, PU was greater in red and white quadriceps than in soleus $(p<0.05-0.001)$. These indices did not differ between red and white quadriceps.

\section{FA compositions in the skeletal muscles in $C A$}

Figures 1 and 2 summarize the results obtained from the muscles of warm controls and cold-exposed rats.

Table 1. Fatty acid (FA) composition ( $\mathrm{mol}_{0} \%$ ) of rat chow used in the present study.

\begin{tabular}{|c|c|c|c|c|c|c|c|c|c|c|c|}
\hline & $\mathrm{Cl} 4$ & $\mathrm{C} 16$ & $\mathrm{C} 16: 1$ & $\mathrm{C} 18$ & C18: 1 & $\mathrm{C} 18: 2$ & $\mathrm{C} 18: 3$ & $\mathrm{C} 20: 4$ & SA & $\mathrm{MU}$ & PU \\
\hline TG & 0.7 & 13.9 & $0 . i$ & 22.7 & 56.7 & 5.2 & 0.1 & 0 & 37.3 & 57.4 & 5.3 \\
\hline PL & 0.9 & 44.3 & 1.2 & 28.3 & 9.1 & 16.0 & 0.2 & 0 & 73.5 & 10.2 & 16.2 \\
\hline
\end{tabular}

TG, triglyceride; PL, phospholipid; SA, saturated fatty acids (FA); MU, monounsaturated FA; PU, polyunsaturated FA. 

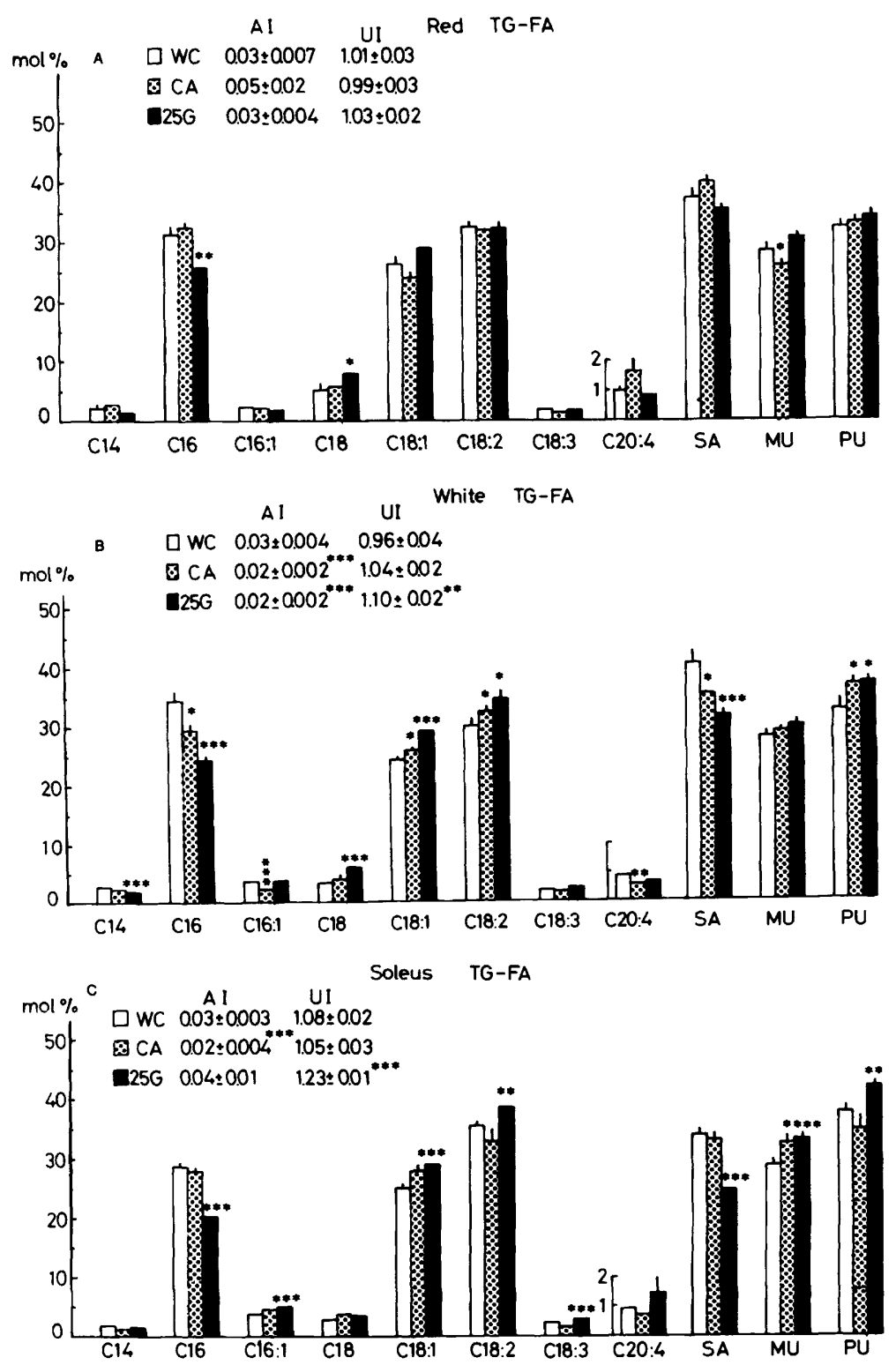

Fig. 1. Changes in fatty acid (FA) composition of triglyceride (TG) in skeletal muscles in cold-exposed rats. A: red quadriceps; B: white quadriceps; C: soleus. WC, warm controls; CA, cold-acclimated rats; $25 \mathrm{G}$, rats reared in cold for 25 generations; AI, arachidonate index (C20:4/C18:2); UI, unsaturation index. C14, myristate; $\mathrm{C} 16$, palmitate; $\mathrm{C} 16: 1$, palmitoleate; $\mathrm{C} 18$, stearate; $\mathrm{C} 18: 1$, oleate; $\mathrm{C} 18: 2$, linoleate; $\mathrm{C} 18: 3$, linolenate; $\mathrm{C} 20: 4$, arachidonate. SA, saturated FA; MU, monounsaturated FA; PU, polyunsaturated FA. Vertical bar indicates standard error. Each group consists of 9-20 animals. $*, * *, * * * p$ vs. $\mathrm{WC}<0.05,<0.01$, and $<0.001$, respectively. 


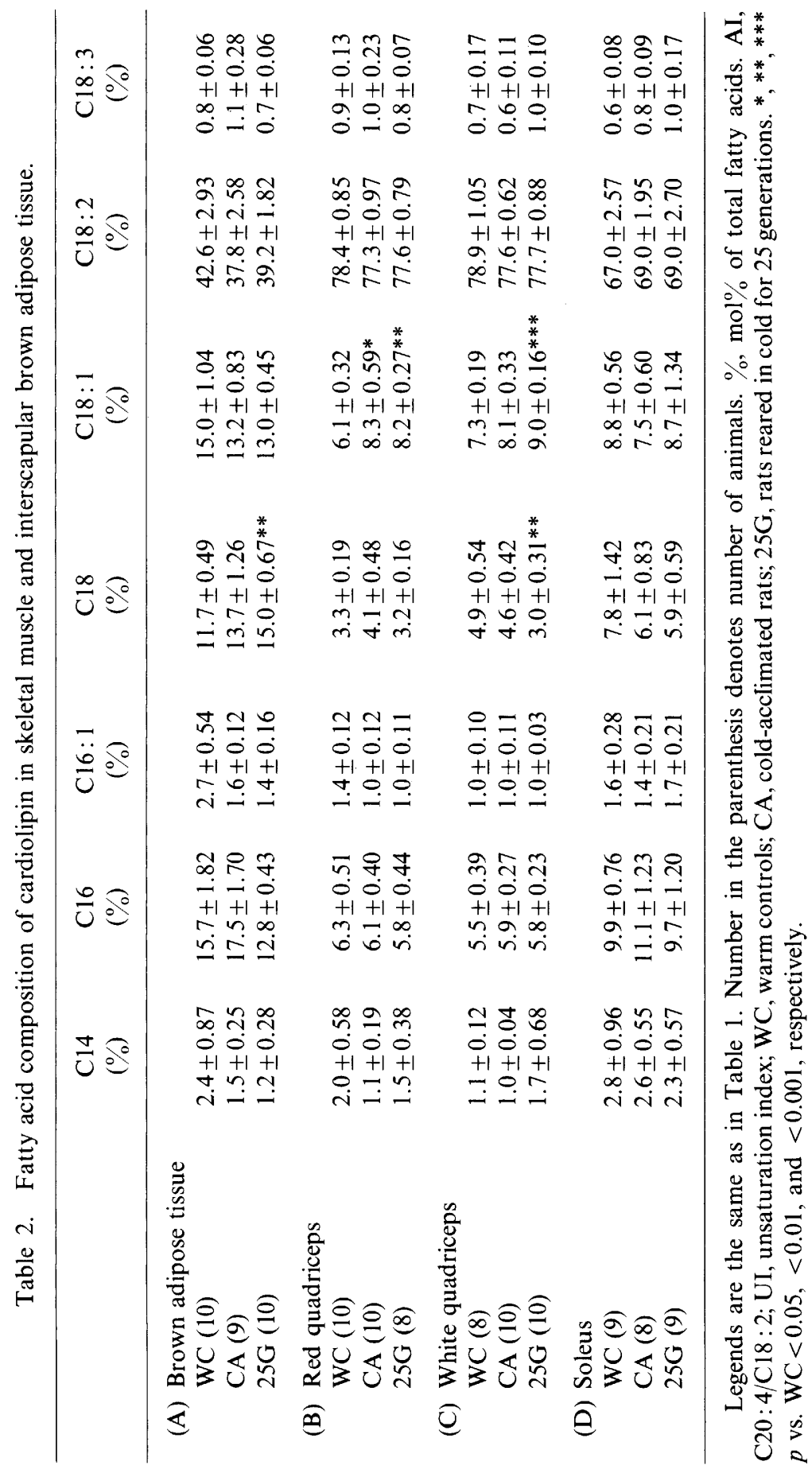




\begin{tabular}{|c|c|c|c|c|}
\hline 2 & 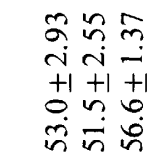 & 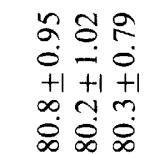 & 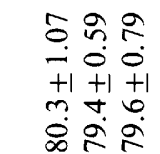 & 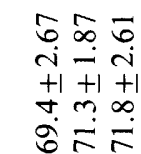 \\
\hline$\sum 0^{0}$ & 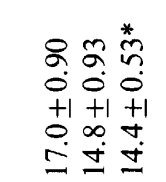 & 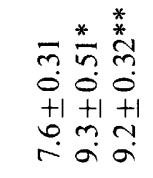 & 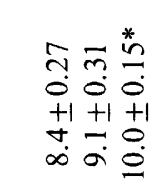 & 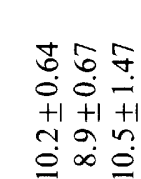 \\
\hline « & 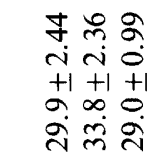 & 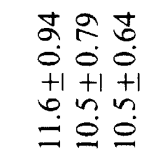 & 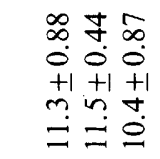 & 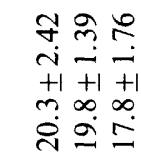 \\
\hline 5 & 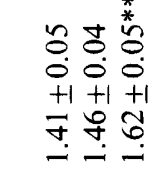 & 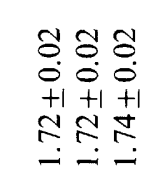 & 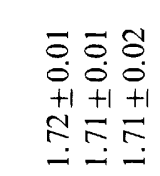 & 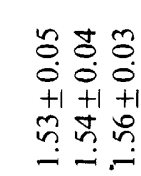 \\
\hline 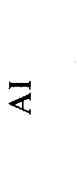 & 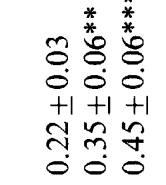 & 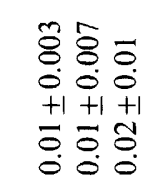 & 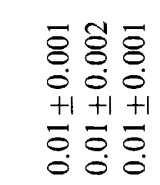 & 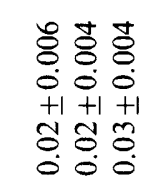 \\
\hline$\ddot{\circlearrowright}$ & 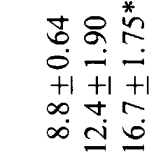 & 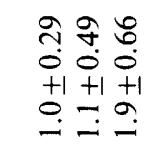 & 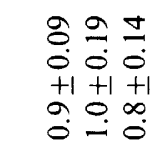 & 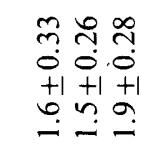 \\
\hline & 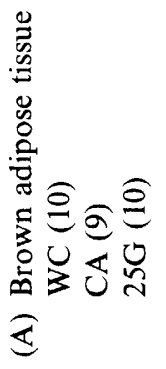 & 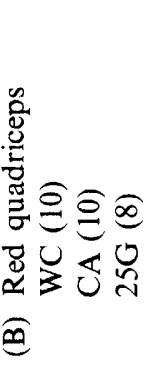 & 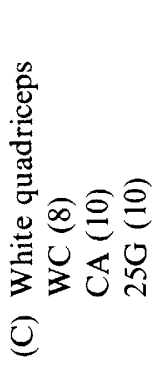 & 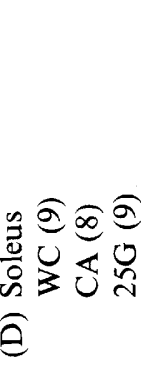 \\
\hline
\end{tabular}

Vol. 37, No. 5, 1987 


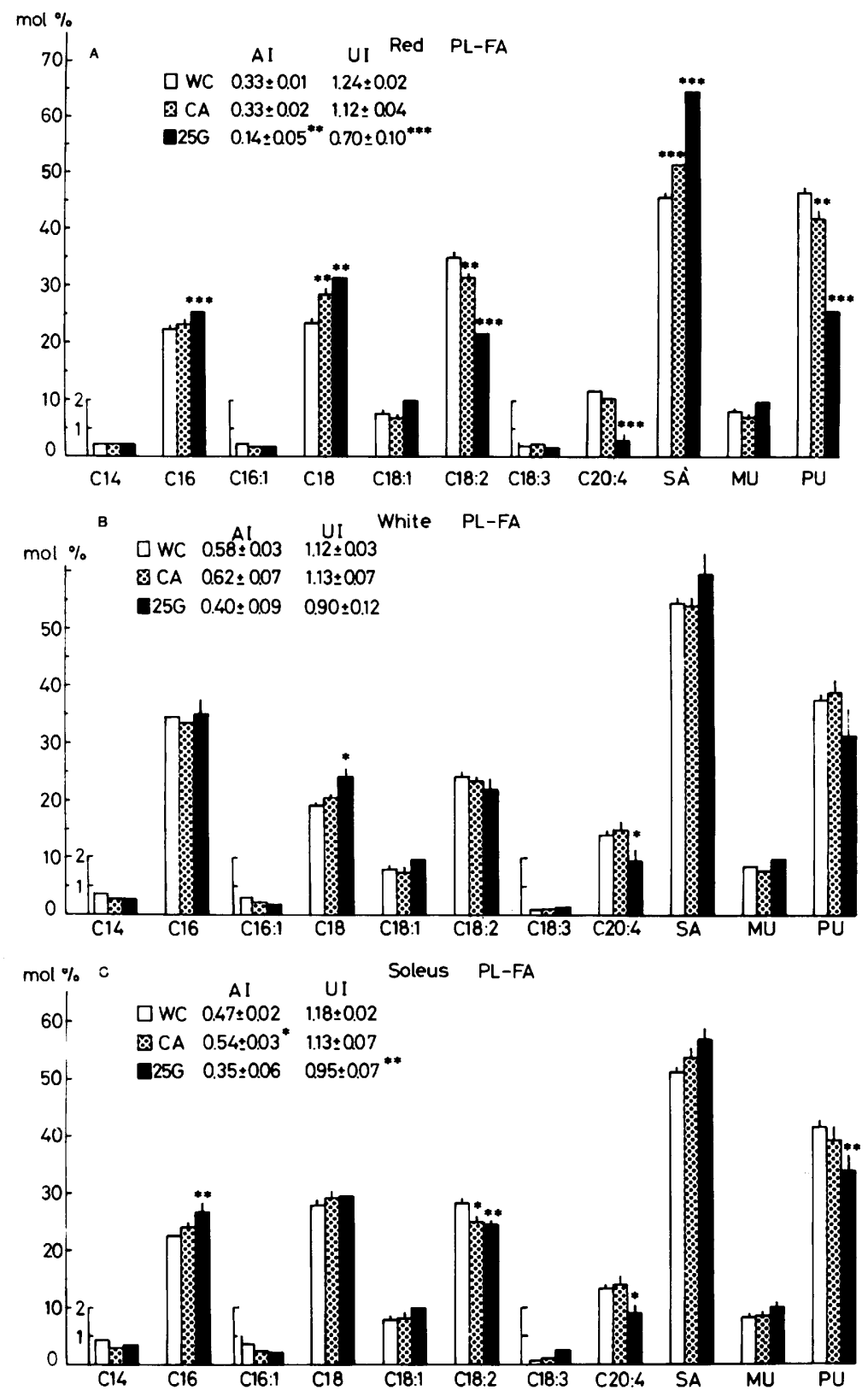

Fig. 2. Changes in FA composition of phospholipid (PL) in skeletal muscles in CA. Legends are the same as in Fig. 1 

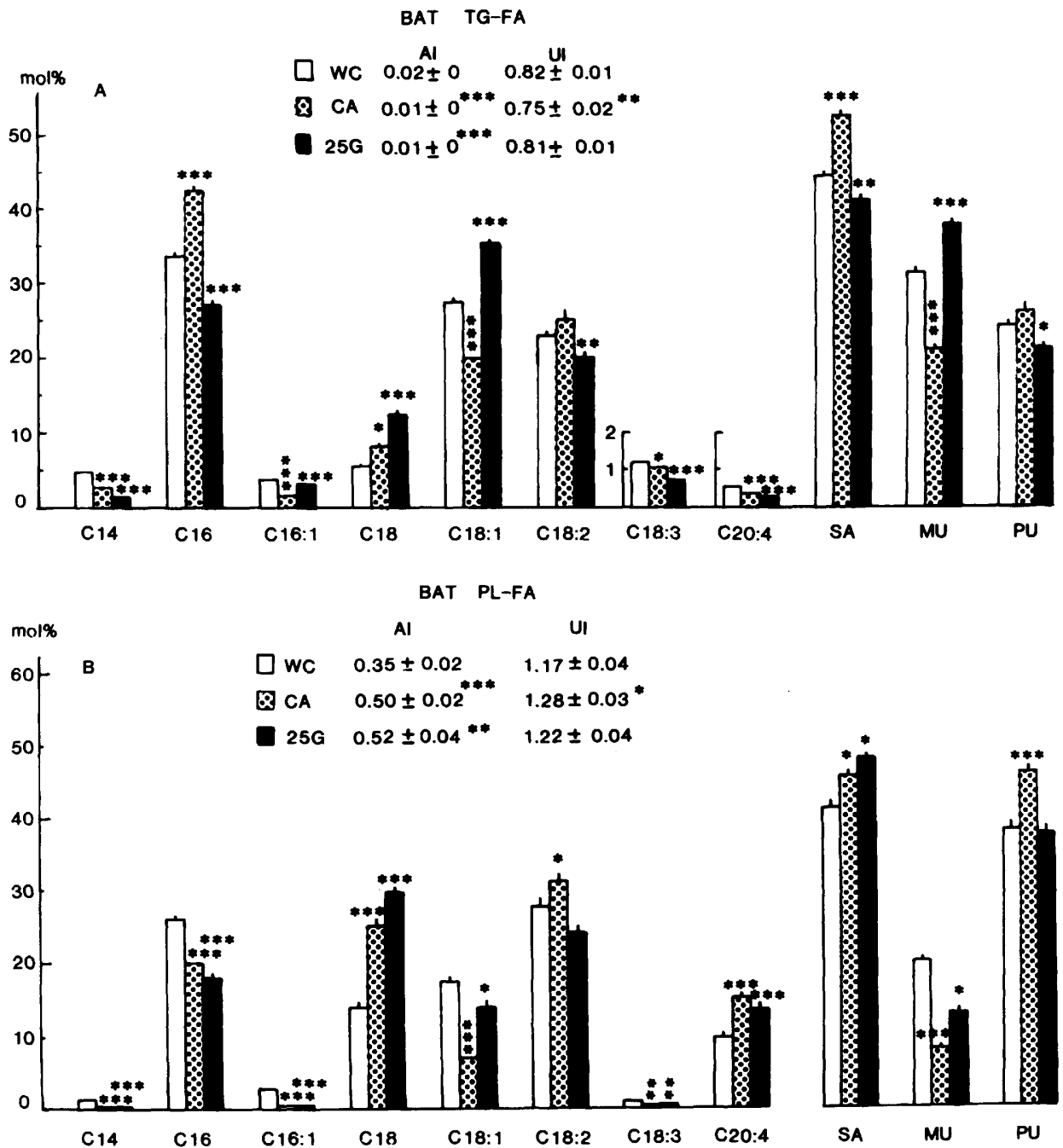

Fig. 3. Changes in FA composition of brown adipose tissue (BAT) in cold-exposed rats. A: TG; B: PL. Legends are the same as in Fig. 1.

TG (Fig. 1). In red quadriceps, MU decreased and in soleus MU increased. In white quadriceps, SA decreased and PU increased.

$P L$ (Fig. 2). In red quadriceps, SA increased and PU decreased, but in white quadriceps and soleus no changes were observed. AI was significantly elevated in soleus.

$C L$ (Table 2). C18:1 and MU significantly increased in red quadriceps, but not in white quadriceps and soleus. 
FA compositions in the skeletal muscles in $25 G$

$T G$ (Fig. 1). PU increased and SA decreased in white quadriceps, MU and PU increased and SA decreased in soleus, while no changes were found in red quadriceps.

PL (Fig. 2). No significant changes were found in white quadriceps, while PU and UI decreased in red quadriceps and soleus. It was also noted that all muscles contained less arachidonate.

$C L$ (Table 2). C18:1 and MU significantly increased in both red and white quadriceps. $\mathrm{C} 18$ decreased in white quadriceps. No significant changes were observed in soleus.

\section{FA compositions in BAT}

As shown in Fig. 3, C20:4, PU, AI, and UI were higher $(p<0.001)$ in PL than in TG. C20:4 was not different between PL and CL, while C18:2 was markedly higher $(p<0.001)$ in CL than PL, resulting in higher UI $(p<0.01)$, PU $(p<0.001)$, and lower SA $(p<0.001)$ (Fig. 3, Table 2).

$T G$ (Fig. $3 A$ ). In CA, SA increased; MU, AI, and UI decreased. In 25G, MU increased; SA and PU decreased.

PL (Fig. 3B). In CA, SA, PU, AI, and UI increased; MU decreased. In 25G, SA increased, MU decreased. C20:4 increased in both CA and 25G.

$C L$ (Table 2). AI increased $(p<0.01)$ in CA. C20:4 $(p<0.001)$, AI $(p<0.001)$, and UI $(p<0.01)$ increased; MU decreased $(p<0.05)$ in $25 \mathrm{G}$.

\section{DISCUSSION}

The skeletal muscles examined in the present study are known to be composed of different types of fibers: white quadriceps has fast-twitch fibers with a low respiratory capacity, red quadriceps has fast-twitch fibers with a high respiratory capacity, and soleus consists of $85 \%$ slow-twitch fibers with a moderately high respiratory capacity and $15 \%$ fast-twitch fibers with a high respiratory capacity (SPRIET et al., 1985 for references). It was noted in the present study that there were site-differences in TG-FA compositions, which may result from the different utilization rates of different FA in the different muscles. Moreover, the present findings that TG-FA compositions were significantly modified in CA and 25G suggest that selective utilization of FA as energy sources in skeletal muscles and BAT was effected by cold exposure. However, there were no consistent patterns of these changes in FA compositions. The changes differed in different muscles and BAT, and between CA and 25G. Several studies indicated the cold-induced unsaturation in depot white fat of rats (MORIYA and ITOH, 1969 for references), while brown adipose tissue did not show any significant changes in TG-FA composition after cold acclimation (Williams and Platner, 1967; Moriya and ITOH, 1969; RiQUIER et al., 1976), where the mobilized fatty acids from depot fat of this tissue are utilized in itself for heat production (NiCHOLLS and LocKE, 1984). The 
present study, however, showed that cold acclimation did induce some changes in TG-FA profiles of BAT as well as skeletal muscles. Therefore, it is likely that FA utilization as energy source is preferentially influenced in these tissues by cold acclimation.

More PU as well as SA and less MU were present in PL-FA than in TG-FA in all muscles examined (Table 2). The difference in PU was most conspicuous in C20:4, which contributed mainly to the increase in PU of PL-FA. These results suggest that PU, especially represented by $\mathrm{C} 20: 4$, play a significant role in the functions of cellular membrane. It has been claimed that a rise in unsaturated FA of PL would exert beneficial changes in the cellular membrane (THOMAS et al., 1977, SPECTOR and YoreK, 1985). RicQuier et al. (1976) reported that the PL of brown adipose tissue from cold-acclimated rats contained more $\mathrm{C} 20: 4$, showing the general trend towards an unsaturation. In agreement with their finding the present result for BAT-PL in CA indicated higher unsaturation as assessed by $\mathrm{C} 20: 4, \mathrm{PU}$, $\mathrm{AI}$, and UI, while no increases were observed in PU and UI of BAT-PL in 25G, although C20:4 and AI significantly increased.

It is well known that mitochondria contain most of cell $\mathrm{CL}$ and a considerable proportion of cell C18:2 (GetZ et al., 1962: Okuyama and Nojima, 1965). CL occurs, in particular, in the inner membrane of mitochondria and is suspected of playing an important role in operation of thermogenesis. The present results confirmed such predominant occurrence of $\mathrm{C} 18: 2$ and high unsaturation in CL as compared with PL in BAT as well as skeletal muscles (Figs. 2,3, Table 2). In this BAT-CL, higher C20:4, AI, and UI in $25 \mathrm{G}$, and higher AI in CA were observed (Table 2). Therefore, it is likely that unsaturation in CL is more closely associated with an enhanced NST in BAT. RICQUIER et al. (1975) also reported alterations of FA distribution of BAT-CL in CA: a decrease of C18:1 and an increase of C18:2, which did not correspond to the present results.

PU of PL-FA rather decreased in the red quadriceps of CA and $25 \mathrm{G}$, and in the soleus of $25 \mathrm{G}$, while significant increases in MU of CL-FA of red quadriceps of CA, and in that of red as well as white quadriceps of $25 \mathrm{G}$ were found (Fig. 2, Table 2). The results indicate more unsaturation of CL-FA, but less unsaturation in PL-FA, in the skeletal muscles of CA and 25G.

Therefore, if an unsaturation in mitochondrial CL-FA is specifically associated with thermogenic function, the present results suggest that the skeletal muscles are involved in an enhanced NST during cold acclimation through an increased unsaturation of CL-FA.

However, it should be noted that the manners of cold-induced changes in CLFA of skeletal muscles differ from those of BAT: the increased MU, and the increased AI, UI and $\mathrm{C} 20: 4$, respectively. PU in the skeletal muscles was considerably higher $(p<0.001)$ as compared with that in BAT. Thus, the above difference between the skeletal muscles and BAT may result from the different metabolic machinery in the different tissue. It is well established that BAT possesses a unique uncoupling protein across the mitochondrial inner membrane, but not 
other tissues (AFONG et al., 1985). It is not yet possible to make conclusive generalization how any changes in FA profile in cellular membrane component could influence cellular functions. However, it is possible that the changes in membrance FA composition actually could occur under various conditions and affect cellular functions (DAUM, 1985; SPECTOR and YOREK, 1985). The changes observed here may reflect certain modifications in the metabolic activity of skeletal muscles as well as BAT induced by cold acclimation.

Exercise training has been also shown as a physiological stimulus to modify FA compositions in the skeletal muscles in men (ThOMAs et al., 1977) and in rats (IWAGAKI and KAZAMI, 1985). In trained men, PL-FA of white quadriceps contained more $\mathrm{C} 18: 2$, and less $\mathrm{C} 16$, while in trained rats $\mathrm{C} 18: 2$ decreased in all $\mathrm{PL}$ fractions of soleus, but it increased in $\mathrm{CL}$ of heart.

Although further studies are needed to determine the physiological relevance of the changes in FA observed here in respect to a role of skeletal muscle in cold acclimation, they would apparently indicate certain roles of membrane, especially mitochondrial FA in the metabolic changes in the skeletal muscle metabolism.

\section{REFERENCES}

Afong, M., Olynyk, K. A., and Patel, H. (1985) Immunological studies of the uncoupling protein of brown adipose tissue. Can. J. Biochem. Cell. Biol., 63: 96-101.

Begin-Heick, N. and Heick, H. M. C. (1977) Increased lipoprotein lipase activity of skeletal muscle in cold-acclimated rats. Can. J. Biochem., 55: 1241-1243.

Behrens, W. A. and Himms-HaGEN, J. (1977) Alterations in skeletal muscle mitochondria of cold-acclimated rats: Association, with enhanced metabolic responses to noradrenaline. J. Bioenerg. Biomembr., 9: 41-63.

Daum, G. (1985) Lipids of mitochondria. Biochim. Biophys. Acta, 822: 1-42.

DeBris, V. I. and FilipChENKo, R. E. (1975) Histochemical and cytophotometrical study on succinate dehydrogenase activity in skeletal muscle of cold-adapted rat. In: Physiological Adaptation to Cold, High-Land and Subarctic Environments, ed. by IvanOv, K. P. and SLonim, A. D., Nauka, Novosibirsk, pp. 17-25.

Folch, J., Lees, M., and Stanley, G. H. S. (1957) A simple method for the isolation and purification of total lipides from animal tissues. J. Biol. Chem., 226: 497-509.

Foster, D. O. and Frydman, M. L. (1979) Tissue distribution of cold-induced thermogenesis in conscious warm- or cold-acclimated rats reevaluated from changes in tissue blood flow. The dominant role of brown adipose tissue in the replacement of shivering by nonshivering thermogenesis. Can. J. Physiol. Pharmacol., 57: 257-270.

Getz, G. S., Bartley, W., Stirpe, F., Notton, B. M., and Renshaw, A. (1962) The lipid composition of the rat-liver mitochondria, fluffy layer and microsomes. Biochem. J., 83: $181-191$.

GrubB, B. and Folk, G. E., Jr. (1976) Effect of cold acclimation on norepinephrine stimulated oxygen consumption in muscle. J. Comp. Physiol., 110: 217-226.

Guernsey, D. L. and Stevens, E. D. (1977) The cell membrane sodium pump as a mechanism for increasing thermogenesis during cold acclimation in rats. Science, 196: 908-910.

Harms, S. J. and Hickson, R. C. (1983) Skeletal muscle mitochondria and myoglobin, 
endurance, and intensity of training. J. Appl. Physiol., 54: 798-802.

Hollenberg, C. H. and Douglas, D. E. (1962) Effect of adrenaline, corticotropin, fasting and diabetes on the composition of the long-chain fatty acids of rat epididymal fat. Nature, 193: 1074-1075.

Hunter, J. D., BuChanAN, H., and Nye, E. R. (1970) The mobilization of free fatty acid in relation to adipose tissue triglyceride fatty acid in the rat. J. Lipid Res., 11: 259-265.

IWAGAKI, S. and KAZAMI, M. (1985) Changes in fatty acid composition of tissue lipids of rats by training. Jpn. J. Phys. Fitness Sports Med. (Suppl.), 34: 203-211.

JANSKÝ, L. and HART, J. S. (1963) Participation of skeletal muscle and kidney during nonshivering thermogenesis in cold-acclimated rats. Can. J. Physiol. Pharmacol., 41: 953-964.

Kinnula, V. L., Huttunen, P., and Hirvonen, J. (1983) Adaptive changes in skeletal muscle mitochondria of the guinea-pig during acclimation to cold. Eur. J. Appl. Physiol., 51: 237-245.

Kurahashi, M. and Kuroshima, A. (1978) Creatine metabolism in skeletal muscle of coldacclimated rats. J. Appl. Physiol., 44: 12-16.

Lafrance, L., Lagace, G., and Routhier, D. (1980) Free fatty acid and oxygen consumption. Effects of noradrenaline in nofasted and nonanesthetized cold-adapted rats. Can. J. Physiol. Pharmacol., 58: 797-804.

MaK, I. T., Shrago, E., and ElsoJ, P. E. (1983) Modification of liver mitochondrial lipids and of adenine nucleotide translocase and oxidative phosphorylation by cold adaptation. Biochim. Biophys. Acta, 722: 302-309.

MoriYA, K. and Ito, S. (1969) Fatty acid composition of brown fat in the rat. Jpn. J. Physiol., 19: 775-790.

Moriya, K., Yahata, T., and Kuroshima, A. (1985) Lasting consistency of cold adaptability in rats reared in cold for many generations. Jpn. J. Physiol., 35: 423-442.

Morrison, W. R. and Smith, L. M. (1964) Preparation of fatty acid methyl esters and dimethylacetals from lipids with boron fluoride-methanol. J. Lipid Res., 5: 600-608.

NichOLls, D. D. and LoCKE, R. M. (1984) Thermogenic mechanisms in brown fat. Physiol. Rev., 64: 1-64.

Ohno, T. and Kuroshima, A. (1986) Muscle myoglobin as determined by electrophoresis in thermally acclimated rat. Jpn. J. Physiol., 36: 733-744.

Okuyama, H. and Nojima, S. (1965) Studies on hydrolysis of cardiolipin by snake venom phospholipase A. J. Biochem., 57: 529-538.

PAULSRUd, J. R. and DrYeR, R. L. (1968) Circum-annual changes in triglyceride fatty acids of fat brown adipose tissue. Lipids, 3: 340-345.

Pollock, M., Cable, W. J. L., and Tiller, S. H. (1973) Skeletal muscle metabolism in cold acclimation. In: Basic Research in Myology. Part 1, ed. by KaKULAS, B. A., American Elsevier, New York, pp. 102-108.

Ricquier, D., Mory, G., and Hemon, P. (1975) Alterations of mitochondrial phospholipids in the rat brown adipose tissue after chronic treatment with cold or thyroxine. FEBS Lett., 53: 342-346.

Ricquier, D., Mory, G., and Hemon, P. (1976) Effects of chronic treatments upon the brown adipose tissue of young rats. Pfiügers Arch., 362: 241-246.

Simon, G. and Rouser, G. (1967) Phospholipids of the sea anemone: Quantitative distribution; Absence of carbon-phosphorus linkages in glycerol phospholipids; Structural elucidation of ceramide aminoethylphosphonate. Lipids, 2: 55-59.

SkIPSKI, V. P. and BARCLAY, M. (1969) Thin-layer chromatography of lipids. Methods 
Enzymol., 16: 530-597.

Spector, A. A. and Yorek, M. A. (1985) Membrane lipid composition and cellular function. J. Lipid Res., 26: 1015-1035.

Spriet, L. L., Peters, S. J., Heigenhauser, G. J. F., and Jones, N. L. (1985) Rat skeletal muscle triacylglycerol utilization during exhaustive swimming. Can. J. Physiol. Pharmacol., 63: 614 618 .

Thomas, T. R., Londeree, B. R., Gerhardt, K. O., and Gehrke, C. W. (1977) Fatty acid profile and cholesterol in skeletal muscle of trained and untrained men. J. Appl. Physiol., 43: 709-713.

Williams, D. D. and Platner, W. S. (1967) Cold-induced changes in fatty acids of the rat and hamster. Am. J. Physiol., 212: 167-172.

WINDER, W. W. and HolLoszy, J. O. (1977) Response of mitochondria of different types of skeletal muscle to thyrotoxicosis. Am. J. Physiol., 232: C180-C184.

Yahata, T. and Kuroshima, A. (1977) Changes in fine structure of rat skeletal muscle related to cold acclimation. Hokkaido J. Med. Sci., 52: 63-67. 